\title{
Primary culture of Rhodnius prolixus (Hemiptera: Reduviidae) salivary gland cells
}

\author{
Fernanda F Rocha', Ricardo N Araujo', Luciana M Silva ${ }^{2}$, Nelder F Gontijo', Marcos H Pereira ${ }^{1 /+}$ \\ ${ }^{1}$ Laboratório de Fisiologia de Insetos Hematófagos, Departamento de Parasitologia, Instituto de Ciências Biológicas, Universidade Federal \\ de Minas Gerais, Caixa Postal 486, 31270-901 Belo Horizonte, MG, Brasil ²Laboratório de Biologia Celular e Inovações Tecnológicas, \\ Diretoria de Pesquisa e Desenvolvimento, Fundação Ezequiel Dias, Belo Horizonte, MG, Brasil
}

In the present paper, we developed a primary culture of Rhodnius prolixus salivary gland and main salivary canal cells. Cells remained viable in culture for 30 days. Three types of cells were indentified in the salivary gland cultures, with binuclear cells being the most abundant. The supernatants of salivary cultures contained mainly 16-24 $k D a$ proteins and presented anticoagulant and apyrase activities. Secretion vesicles were observed budding from the cellular monolayer of the main salivary canal cells. These results indicate that $\mathrm{R}$. prolixus salivary proteins may be produced in vitro and suggest that the main salivary canal may have a possible secretory role.

Key words: Rhodnius prolixus - salivary gland - primary culture

Triatomines are insects that are haematophagous throughout the nymphal stages and as adults. They are vectors of the trypanosomatids Trypanosoma cruzi and Trypanosoma rangeli. To obtain a successful blood meal, triatomines produce a diverse set of molecules in their salivary glands that are released at the bite site during the feeding process (Soares et al. 2006) in order to counteract homeostasis, inflammation and immune responses from their vertebrate hosts (Ribeiro 1995).

The salivary apparatus of Rhodnius prolixus is composed of the salivary pump, the salivary canals and the salivary glands. The main salivary glands are two independent, elongated compartments found parallel to the oesophagus. Each main gland has a small transparent vesicle called the accessory gland (Perez 1969).

In triatomines, the main salivary glands are composed of a single layer of epithelial cells that surrounds the large central lumen and a thin basal lamina containing tracheolae, muscle fibres/myofibrils (Barth 1954, Lacombe 1999, Reis et al. 2003) and neuronal terminations (Meirelles et al. 2003). The morphology of the cells is still not completely known. In Rhodnius domesticus, Meirelles et al. (2003) showed that the main salivary glands have mononuclear cells, whereas Anhê et al. (2007) described binucleated cells in both the main salivary gland and the accessory gland from $R$. prolixus and Rhodnius neglectus.

The salivary canal originates from the main salivary gland and transports the saliva to the salivary pump. In $R$. domesticus, the canal is composed of epithelial cells

Financial support: CAPES, CNPq, FAPEMIG

+ Corresponding author: marcoshp@icb.ufmg.br

Received 14 October 2009

Accepted 5 March 2010 covered by a basal lamina with tracheolae (Meirelles et al. 2003). The salivary pump forces the saliva through the canal and delivers it to the bite site (Perez 1969).

In $R$. prolixus, proteins belonging to the lipocalin family are the most abundant and diverse molecules in the saliva (Andersen et al. 2005). They include the notriphorins 1-7 (Champagne et al. 1995, Moreira et al. 2003, Knipp et al. 2007), biogenic amine binding proteins (Andersen et al. 2003) and ADP-binding proteins known as Rhodnius platelet aggregation inhibitor (Francischetti et al. 2000) as well as uncharacterised molecules related to Triatoma pallidipennis thrombin inhibitor triabin (Fuentes-Prior et al. 1997). In addition to the lipocalins, salivary components include apyrase (Ribeiro \& Garcia 1981) and anti-haemostatic phospholipids, such as lysophosphatidylcholine (Golodne et al. 2003), as well as inhibitors of the complement system (Barros et al. 2009). In addition, novel molecules were identified in the study of the R. prolixus sialome (Ribeiro et al. 2004).

The molecular diversity of haematophagous insect saliva could lead to the identification of potential pharmacologically active compounds and could help to elucidate the evolutionary mechanisms of insect adaptation to haematophagy (Ribeiro et al. 2004). Thus, the present work aims to obtain a primary culture of the main salivary gland and salivary canal cells of $R$. prolixus in order to produce pure in vitro salivary compounds to be used in studies of identification and characterisation of novel bioactive molecules. The cultivation of $R$. prolixus salivary glands could also be useful in studying its interaction with $T$. rangeli.

The salivary glands (main and accessory glands) and the salivary canal were isolated from both male and female adult $R$. prolixus at $24 \mathrm{~h}$ or 5 days after feeding. Insects were anaesthetised on ice, disinfected by immersion in detergent (diluted to $5 \%$ in distilled water) for $2 \mathrm{~min}$ and immersed in $1 \% \mathrm{NaClO}$ for $2 \mathrm{~min}$ and in $70 \%$ ethanol for $5 \mathrm{~min}$. The organs were isolated under aseptic conditions using a laminar flow cabinet. The cul- 
tivation was carried out using the media IPL-41 (components weighed individually), TNM-FH (Sigma), Grace's (Sigma) and Schneider's (Sigma) supplemented with 30 $\mathrm{mg} / \mathrm{mL}$ tryptose phosphate (Sigma), 20\% inactivated fetal calf serum (FCS), $10 \mu \mathrm{g} / \mathrm{mL}$ mice epidermal growth factor (Sigma), $45 \mathrm{mg} / \mathrm{mL}$ glucose (Sigma), $30 \mathrm{mg} / \mathrm{mL}$ glutamine (Sigma), $2 \mathrm{mg} / \mathrm{mL}$ insulin (Sigma), 10X insect medium supplement (low protein $<150 \mu \mathrm{g} / \mathrm{mL}$ ) (Sigma), $10 \mathrm{mg} / \mathrm{mL}$ tetracycline (Sigma), $2.5 \mathrm{mg} / \mathrm{mL}$ anfotericin $\mathrm{B}$ (Sigma) and $50 \mathrm{mg} / \mathrm{mL}$ gentamicin (Sigma) at pH 7.0.

The salivary glands were shred with entomological scissors and treated with type XI collagenase at a concentration of $2 \mathrm{mg} / \mathrm{mL}$ for $20 \mathrm{~min}$ and at $4 \mathrm{mg} / \mathrm{mL}$ for $40 \mathrm{~min}$ at RT. The salivary canal was not treated due to high cell sensitivity to enzymatic treatment. The tissues (15 salivary glands/well or 15 salivary canals/well) were cultivated in 6 -well plates containing $25 \mu \mathrm{L}$ of culture medium at $28^{\circ} \mathrm{C}$ in a humid chamber. The use of higher volumes of medium and wells with smaller diameters induced less cell adhesion and permitted the adhesion of the cells to the walls rather than to the bottom of the plate. The medium was replaced every five days. Culture supernatants were collected and maintained at $-20^{\circ} \mathrm{C}$ until use.
Among all culture media tested, the best cellular adhesion was obtained with Schneider's insect medium (Sigma). The collagenase treatment enabled a clearer visualisation of the cell types of the salivary glands with less cellular damage. Glands and canals isolated $24 \mathrm{~h}$ after feeding had higher number of adherent cells and were used for the cultures.

Salivary gland cultures were analysed directly on the plates (Fig. 1) or after staining with Giemsa (data not shown) under an optic microscope. Three types of cells were observed in the salivary gland culture. The type I cells were elongated and fusiform and migrated from the tissue fragments to the edge of the plate wells (Fig. 1A). Cell migration started four days after the beginning of the culture and was observed until approximately 15 days of cultivation. These cells were abundant in the gland cultures. Type II cells were the most common in culture. They presented a globular shape with two evident nuclei (Fig. 1B) and could be visualised in cell clumps (Fig. 1D). Type III cells were rare and presented a globular shape with a unique nucleus (Fig 1C). Previous studies suggested that binucleated salivary gland cells may be responsible for saliva production and secretion. These cells have the largest nuclear mass, which
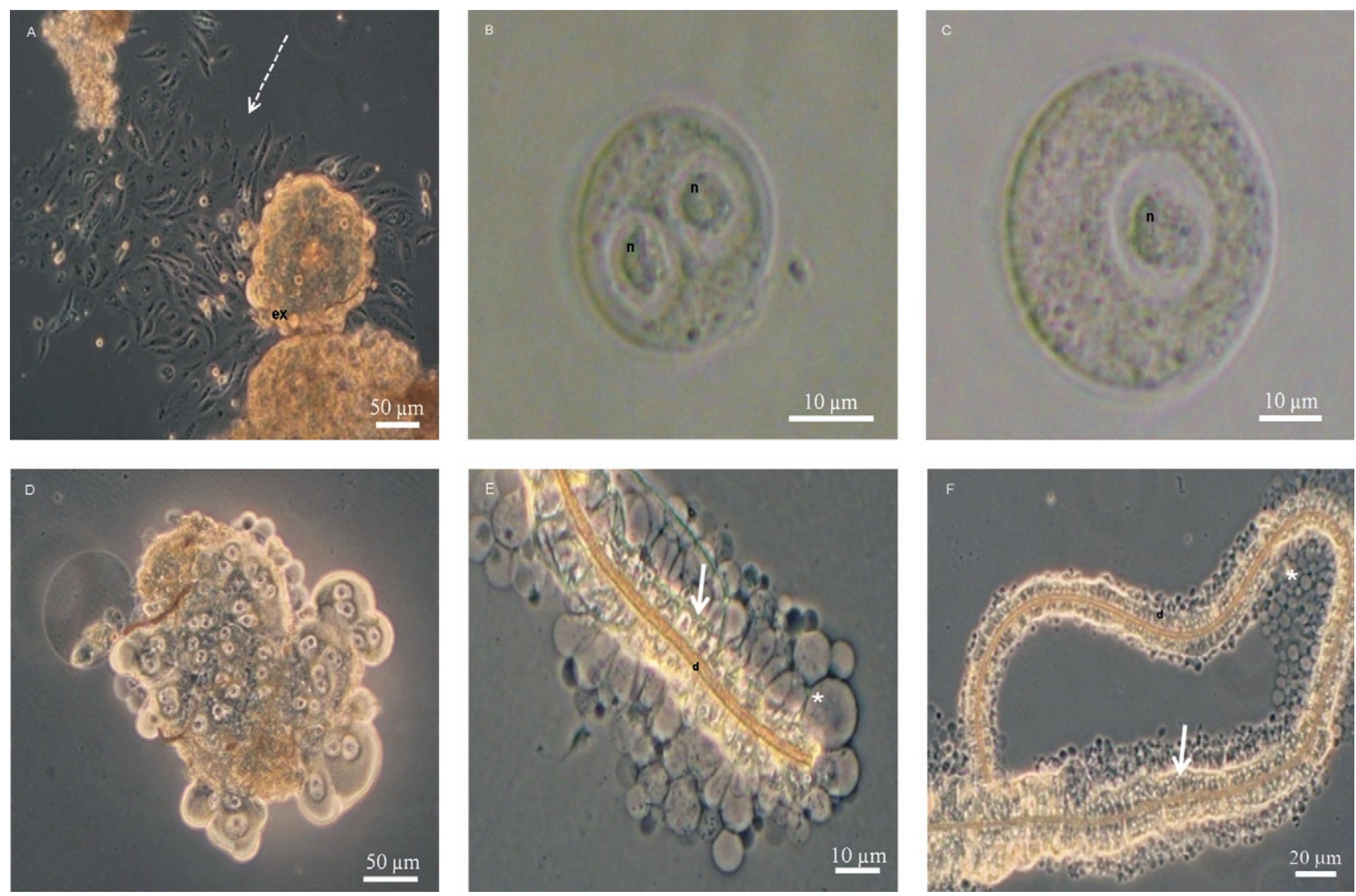

Fig. 1: primary culture of Rhodnius prolixus salivary gland and salivary canal cells. Photos were taken directly from the culture plates with no treatment. A: explants of salivary gland presenting type I cell migration with fusiform shape cells at day 7 of cultivation; B: close view of type II cells; C: close view of type III cells; D: overview of explants; E: close view of salivary canal; F: general view of salivary canal. Photos B-F were taken at day 12 of cultivation; d: salivary duct; ex: explants; n: nucleus; --- : type I cell; $\rightarrow$ : monolayer of juxtaposed cells; *: secretion granules. 
A

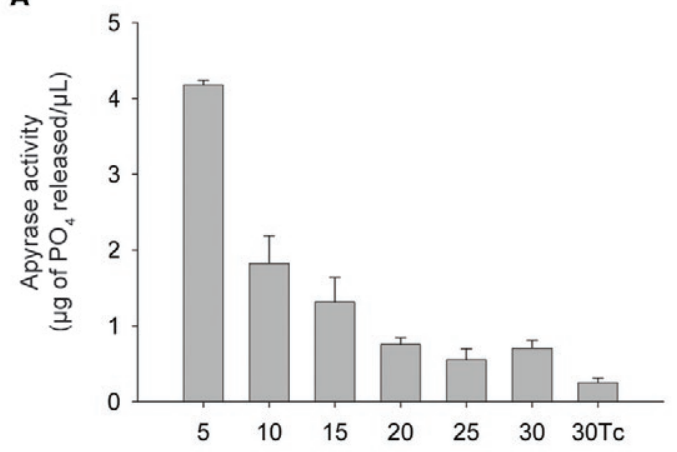

C

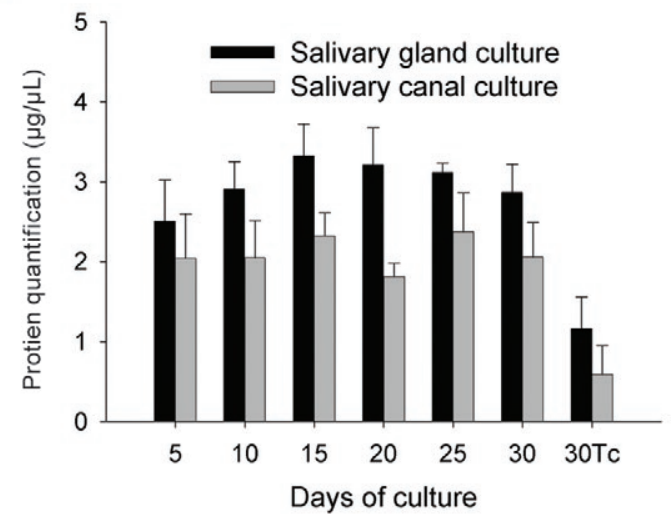

B
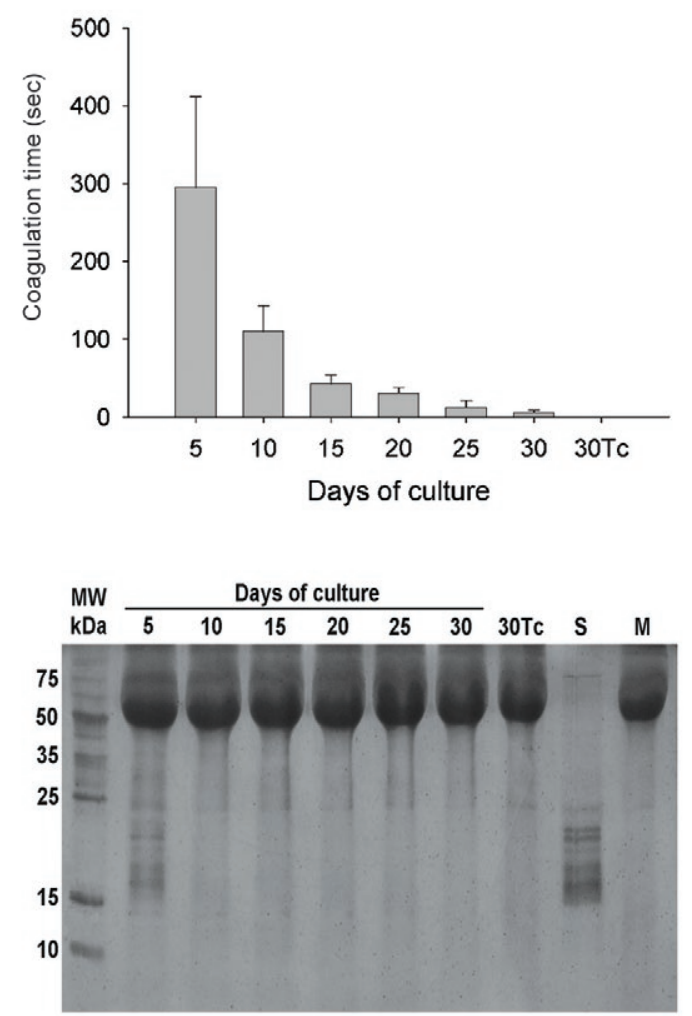

Fig. 2: biological activities and protein content from the supernatant of Rhodnius prolixus salivary gland cultures. Measurements were performed according to Araujo et al. (2006). Bars $=$ mean \pm standart error of 5 pools. Each pool is the supernatant of two cultures. $5 \mu \mathrm{L}$ of the supernatant were used for the apyrase and anticoagulant assays. Values on graphs were subtracted from values of the medium alone. A: apyrase activity; B: plasma recalcification time assay; C: protein quantification; D: 15\% SDS-PAGE; M: culture medium; MW: molecular weight standard; S: salivary content; 30Tc: extract of the salivary gland or canal cell culture at day 30 . SDS-PAGE columns contain $2 \mu \mathrm{L}$ from a pool of 5 samples of each culture supernatant, $\sim 6 \mu \mathrm{g}$ of salivary gland extract, $\sim 6 \mu \mathrm{g}$ of saliva and $2 \mu \mathrm{L}$ of medium.

may indicate the higher metabolic activity necessary for rapid and regular cell regeneration (Barth 1954, Anhe \& Azeredo-Oliveira 2008).

The salivary canal cultures presented groups of mononuclear cells arranged in a juxtaposed unique layer that formed the salivary duct (Fig. 1E, F). The canals remained in culture for 30 days. Interestingly, secretion granules could be observed around the cells from the 3rd day of cultivation onwards, reaching higher densities from day 3-16 and remaining present until day 30 of cultivation.

The supernatant of the salivary gland cultures presented both apyrase (Fig. 2A) and anticoagulant (Fig. 2B) activities that were highest at day 5 and decreased over time (Fig. 2A, B). The total amount of soluble proteins remained constant throughout the cultivation (Fig. 2C). SDS-PAGE analysis confirmed the presence of $R$. prolixus salivary proteins, which were best seen at the first days of cultivation (days 5-10) (Fig. 2D). Stronger bands were observed from 16-24 $\mathrm{kDa}$, the approximate molecular weight expected for lipocalins (Ribeiro et al. 2004, Andersen et al. 2005). The presence of FCS in the medium (containing bovine serum albumin and other proteins) impaired the visualisation of proteins higher than $\sim 66 \mathrm{kDa}$.
The total amount of proteins in the supernatant may indicate that the cells are producing proteins with molecular weights not visible in the SDS-PAGE and with activities other than anticoagulant or apyrase. These results are in line with the viability test, which confirmed low levels of cell death from day 5-25 of cultivation (Fig. 3 ), suggesting the supernatant has low levels of intracellular proteins derived from cell disruption.

The detection of salivary proteins in the supernatant after the medium was replaced indicates that the glands are actively secreting proteins. However, the presence of small amounts of proteins derived from cell disruption cannot be disregarded. The viability of the cells reduced with time, probably due to a lack of stimulus (e.g., hormones) in the medium or simply because of the biological cycle of the cells. Previous physiological studies of the salivary gland from Triatoma infestans described that cells entered an inactive state at 10-14 days after feeding. Five minutes after feeding, salivary gland cells were highly active, as characterised by an increased size, resumption of secretion and protoplasmatic regeneration (Barth 1954). These findings are in agreement with our results, in which more cells were adherent to plates in 

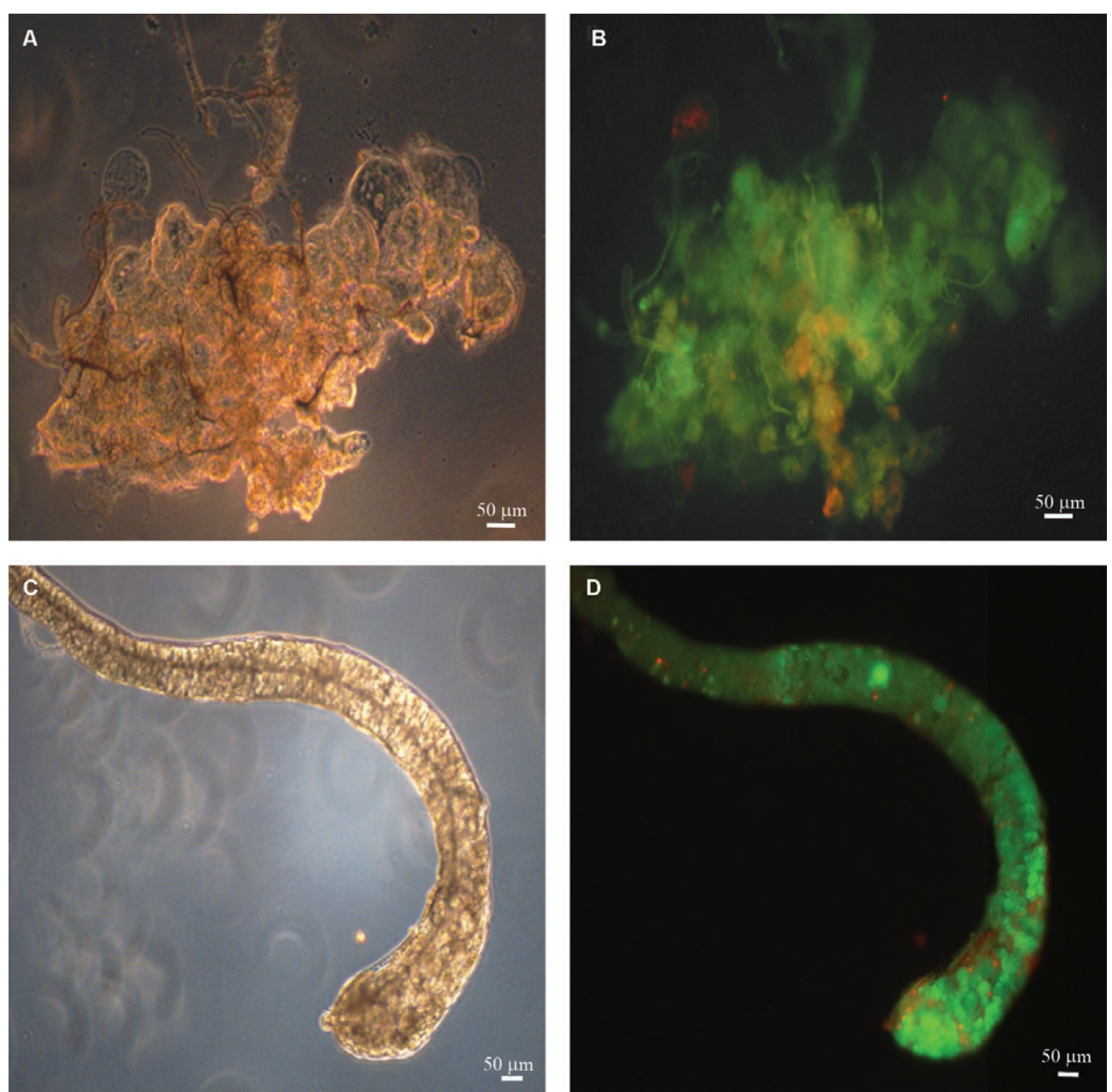

Fig 3: viability test of the cells from the primary cultures of Rhodnius prolixus at day 25 of cultivation. Cells were treated using the Live/Dead Viability/Citotoxicity kit (Molecular Probes ${ }^{\circledR}$ ) according to manufacture instructions. The treatment was performed on the culture plates followed by photo documentation. A and C are phase contrast and B and D fluorescent view under optical microscope. Alive cells are marked green (excitation/emission 495/515 nm) and dead cells red (495/635 nm). A, B: salivary gland; C, D: salivary canal.

culture when isolated from salivary glands $24 \mathrm{~h}$ after feeding, with their highest protein activity observed in the supernatant within the first days of culture. Marshall (1982) maintained Triatoma protracta salivary glands in tubes containing culture medium for 35 days; the results of that study suggested that a constant level of protein is produced during the cultivation period. The supernatant collected on different days was injected intradermically and produced a similar area of wheal and erythema.

Protein quantitation indicated that the salivary canal produced and secreted molecules in the supernatant until the end of cultivation (Fig. 2C). Such values correspond with the identification of granules in cells of the salivary canal culture. These molecules were not visible in the SDS-PAGE (probably because they have molecular weights higher than $66 \mathrm{kDa}$ ) and had no anticoagulant or apyrase activities. Therefore, they may exert activities other than counteracting homeostasis, such as activation of salivary proteins (Amino et al. 2001, 2002) or supplementation of saliva with other proteins.
In conclusion, the results of the present paper showed that the salivary gland and the main salivary canal of $R$. prolixus can be cultivated in vitro. The primary cultures can be maintained for more than 30 days, but higher levels of activity in the supernatants were observed mainly in the first days. The presence of secretion vesicles in cells from the salivary canal is a novel finding and together with the possible role of hormones in the production of saliva, should be further investigated.

\section{ACKNOWLEDGEMENTS}

To Dr. Mauricio RV Sant'Anna, from the Liverpool School of Tropical Medicine - UK, for revising the paper.

\section{REFERENCES}

Amino R, Martins RM, Procopio J, Hirata IY, Juliano MA, Schenkman S 2002. Trialysin, a novel pore-forming protein from saliva of hematophagous insects activated by limited proteolysis. J Biol Chem 277: 6207-6213.

Amino R, Tanaka AS, Schenkman S 2001. Triapsin, an unusual activatable serine protease from the saliva of the hematophagous vector 
of Chagas' disease Triatoma infestans (Hemiptera: Reduviidae). Insect Biochem Mol Biol 31: 465-472.

Andersen JF, Francischetti IM, Valenzuela JG, Schuck P, Ribeiro JM 2003. Inhibition of hemostasis by a high affinity biogenic aminebinding protein from the saliva of a blood-feeding insect. $J$ Biol Chem 278: 4611-4617.

Andersen JF, Gudderra NP, Francischetti IM, Ribeiro JM 2005. The role of salivary lipocalins in blood feeding by Rhodnius prolixus. Arch Insect Biochem Physiol 58: 97-105.

Anhe AC, Azeredo-Oliveira MT 2008. Cytochemical characterization of Triatoma infestans and Panstrongylus megistus salivary gland cells (Hemiptera: Reduviidae: Triatominae). Micron 39: 1126-1133.

Anhe AC, Lima-Oliveira AP, Azeredo-Oliveira MT 2007. Acid phosphatase activity distribution in salivary glands of triatomines (Heteroptera: Reduviidae: Triatominae). Genet Mol Res 6: 197-205.

Araujo RN, Santos A, Pinto FS, Gontijo NF, Lehane MJ, Pereira MH 2006. RNA interference of the salivary gland nitrophorin 2 in the triatomine bug Rhodnius prolixus (Hemiptera: Reduviidae) by dsRNA ingestion or injection. Insect Biochem Mol Biol 36: 683-693.

Barros VC, Assumpcao JG, Cadete AM, Santos VC, Cavalcante RR, Araujo RN, Pereira MH, Gontijo NF 2009. The role of salivary and intestinal complement system inhibitors in the midgut protection of triatomines and mosquitoes. PLoS One 4: e6047.

Barth R 1954. Estudos anatômicos e histológicos sobre a subfamilia Triatominae (Heteroptera: Reduvidae). Parte IV. O complexo das glândulas salivares de Triatoma infestans. Mem Inst Oswaldo Cruz 53: 517-585.

Champagne DE, Nussenzveig RH, Ribeiro JM 1995. Purification, partial characterization and cloning of nitric oxide-carrying heme proteins (nitrophorins) from salivary glands of the blood-sucking insect Rhodnius prolixus. J Biol Chem 270: 8691-8695.

Francischetti IM, Ribeiro JM, Champagne D, Andersen J 2000. Purification, cloning, expression and mechanism of action of a novel platelet aggregation inhibitor from the salivary gland of the bloodsucking bug, Rhodnius prolixus. J Biol Chem 275: 12639-12650.

Fuentes-Prior P, Noeske-Jungblut C, Donner P, Schleuning WD, Huber $\mathrm{R}$, Bode W 1997. Structure of the thrombin complex with triabin, a lipocalin-like exosite-binding inhibitor derived from a triatomine bug. Proc Natl Acad Sci USA 94: 11845-11850.
Golodne DM, Monteiro RQ, Graca-Souza AV, Silva-Neto MA, Atella GC 2003. Lysophosphatidylcholine acts as an anti-hemostatic molecule in the saliva of the blood-sucking bug Rhodnius prolixus. J Biol Chem 278: 27766-27771.

Knipp M, Yang F, Berry RE, Zhang H, Shokhirev MN, Walker FA 2007. Spectroscopic and functional characterization of nitrophorin 7 from the blood-feeding insect Rhodnius prolixus reveals an important role of its isoform-specific $\mathrm{N}$-terminus for proper protein function. Biochemistry 46: 13254-13268.

Lacombe D 1999. Anatomia e histologia das glândulas salivares dos triatomíneos. Mem Inst Oswaldo Cruz 94: 557-564.

Marshall N 1982. Allergy to Triatoma protracta (Heteroptera: Reduviidae). II. Antigen production in vitro. J Med Entomol 19: 253-254.

Meirelles RM, Rodrigues IS, Steindel M, Soares MJ 2003. Ultrastructure of the salivary glands of Rhodnius domesticus Neiva \& Pinto, 1923 (Hemiptera: Reduviidae). J Submicrosc Cytol Pathol 35: 199-207.

Moreira MF, Coelho HS, Zingali RB, Oliveira PL, Masuda H 2003. Changes in salivary nitrophorin profile during the life cycle of the blood-sucking bug Rhodnius prolixus. Insect Biochem Mol Biol 33: 23-28.

Perez JR 1969. Estudio sobre la anatomía de Rhodnius prolixus. Rev Venez Sanid Assist Soc 34: 10-98.

Reis MM, Meirelles RM, Soares MJ 2003. Fine structure of the salivary glands of Triatoma infestans (Hemiptera: Reduviidae). Tissue Cell 35: 393-400.

Ribeiro JM, Andersen J, Silva-Neto MA, Pham VM, Garfield MK, Valenzuela JG 2004. Exploring the sialome of the blood-sucking bug Rhodnius prolixus. Insect Biochem Mol Biol 34: 61-79.

Ribeiro JM, Garcia ES 1981. Platelet antiaggregating activity in the salivary secretion of the blood sucking bug Rhodnius prolixus. Experientia 37 : 384-386.

Ribeiro JMC 1995. Insect saliva: function, biochemistry and physiology. In RF Chapman, G Boer (ed.), Regulatory mechanisms of insect feeding, Chapman \& Hall, London, p. 74-97.

Soares AC, Carvalho-Tavares J, Gontijo NF, dos Santos VC, Teixeira MM, Pereira MH 2006. Salivation pattern of Rhodnius prolixus (Reduviidae; Triatominae) in mouse skin. J Insect Physiol 52: 468-472. 